\title{
SURVEI PENERAPAN STRATEGI BERTUTUR YOUTUBER INDONESIA NONSELEBRITIS
}

\author{
Nini Ibrahim \\ Pendidikan Bahasa dan Sastra Indonesia, Fakultas Keguruan dan Ilmu Pendidikan, \\ Universitas Muhammadiyah Prof. DR. HAMKA \\ nini_ibrahim@uhamka.ac.id
}

\begin{abstract}
Abstrak
Penelitian ini bertujuan untuk mengetahui strategi bertutur pada Youtuber Profesional dalam menarik minat masyarakat untuk berlangganan (subscribe). Metode pada penelitian ini yaitu deskriptif kualitatif dengan teknik pengumpulan data secara observasi pada 4 Youtuber Profesional nonselebritis yang merintis saluran mereka dari nol tanpa bermodalkan kepopuleran sebagaimana Youtuber artis yang memang telah populer sebelumnya. Teknik analisis data pada penelitian ini menggunakan teori Brown dan Levinson (1987). Hasil penelitian menunjukkan bahwa para konten kreator Youtube (Youtuber) sebagian besar memanfaatkan strategi bertutur dengan basa-basi menggunakan kesantunan yang positif. Hal tersebut dapat terlihat dari persentase yang menunjukkan sebanyak 33\% Youtuber menggunakan strategi tersebut. Selain itu, strategi selanjutnya yang juga dominan muncul adalah strategi berterus-terang tanpa basa-basi dengan persentase $25 \%$ penggunaan, dan $24 \%$ strategi samar-samar. Strategi bertutur yang jarang muncul adalah strategi dengan basa-basi menggunakan kesantunan yang negatif sebanyak $16 \%$, dan yang paling sedikit muncul adalah strategi diam atau bertutur dalam hati sebanyak $2 \%$.
\end{abstract}

Kata Kunci: Strategi Bertutur, Sosiopragmatik, Youtuber

\begin{abstract}
This study aims to determine the storytelling strategies of professional YouTubers in attracting public interest to subscribe. The method used in this research is descriptive qualitative with observational data collection techniques on 4 non-celebrity professional YouTubers who pioneered their channel from scratch without capitalizing on popularity like Youtuber artists who were already popular before. The data analysis technique in this study uses the theory of Brown and Levinson (1987). The results showed that most of the YouTube creators (Youtuber) took advantage of the small talk strategy using positive politeness. This can be seen from the percentage that shows as much as $33 \%$ of YouTubers use this strategy. In addition, the next strategy that also dominantly emerged was the blunt speech strategy with a percentage of $25 \%$ of use, and $24 \%$ of vague speech strategies. The talk strategy that rarely appears is the small talk strategy using negative politeness as much as $16 \%$, and the least appearing is the silent strategy or talking silently as much as $2 \%$.
\end{abstract}

Keywords: Speech of Strategy, Sociopragmatic, Youtuber

Creative Commons Attribution 4.0 International (CC BY 4.0) 


\section{PENDAHULUAN}

Dewasa ini, media sosial digunakan tidak hanya untuk bersosialisasi, tetapi juga sebagai alat untuk menjual barang/jasa (Ulfiana, 2018; Priambada, 2015; Werdani, dkk., 2020). Seiring perkembangan waktu, wawasan masyarakat akan teknologi pada media sosial pun semakin bergerak dan semakin kritis sehingga peluang-peluang terus terbuka lebar dan membuka keran penghasilan yang bisa dibilang fantastis. Kegiatan bermedia sosial yang menguntungkan dan cukup menjanjikan selain berdagang barang/jasa adalah pada bidang penyiaran melalui media Youtube (Romdonny dan Rosmadi, 2018; Moriansyah, 2015).

Saat ini, banyak Youtuber profesional dengan pengikut jutaan orang (subscriber) terus membuat konten sekreatif mungkin untuk mendapatkan penonton (viewers) sebanyak-banyaknya. Hal ini dilakukan karena semakin banyak pengikut dan penonton, maka akan semakin banyak pula penghasilan yang didapatkan dari Google Adsense. Google Adsense adalah program pengiklanan yang memungkinkan pembuat konten memasang iklan di situs web atau blog, atau video YouTube, dan mendapatkan bayaran saat pengunjung mengkliknya (Giguere, 2005). Artinya, semakin banyak penonton dan pengikut dari seorang Youtuber, semakin banyak juga uang yang dihasilkan. Uang itu dibayarkan oleh pengelola Youtube kepada Youtuber dari para pengiklan yang mempromosikan iklannya di dalam video yang diunggah oleh Youtuber tersebut (Artero, 2010).

Karena begitu menjanjikannya bisnis di Youtube ini, akhirnya banyak masyarakat yang berlomba-lomba membuat channel (saluran) Youtube mereka guna meraih pengikut (Cecariyani dan Sukendro, 2018; Rini dan Imran, 2017). Di Indonesia sendiri, Youtuber yang paling banyak memiliki pengikut berdasarkan data statistik tanggal 25 April 2020 adalah: 1) Atta Halilintar (Youtube: Atta Halilintar), 2) Ria Ricis (Youtube: Ricis Official), 3) Keluarga Halilintar (Youtube: Gen Halilintar), 4) Trans7 (Youtube: Trans7 Official), dan 5) Rafi Ahmad dan Nagita Slavina (Youtube: Rans Entertainment) (id.influencer.com, 2020).

Jika dilihat dari peringkat di atas, banyak Youtuber yang berlatar belakang artis/figur publik seperti Rafi Ahmad dan Ria Ricis, maupun instansi populer seperti Trans7 yang memang di awal telah memiliki banyak penggemar (fans). Akan tetapi, banyak juga para Youtuber yang bukan berlatar belakang artis namun tetap memiliki pengukut yang mencapai jutaan seperti: 1) Jess No Limit (Channel game, 12,7 juta pengikut), 2) MiawAug (Channel game, 9,57 juta pengikut), 3) Yudist Ardana (Channel hiburan, 7,64 Juta pengukut), 4) Tanboy Kun (Channel hiburan, 7,56 juta pengikut, 5) Gadgetin (Channel Teknologi, 4,51 Juta pengkikut), dan masih banyak lagi (id.influencer.com, 2020).

Para Youtuber tersebut di atas berlomba-lomba membuat konten dengan bidangbidang tertentu seperti hiburan, komedi, review tempat wisata, review makanan (food vlogger), game, teknologi, dan sebagainya. Video-video yang mereka ciptakan dibuat dengan sinematografi maksimal sehingga memanjakan para penonton yang menyaksikan tayangan mereka berlama-lama. Sinematografi adalah sebuah cara dalam pembuatan film yang meliputi sudut gambar, pergerakan gambar, komposisi gambar, dan tata cahaya (Harahap, 2019; Riyadi, 2014; Cikita dan Murwonugroho, 2018; Junaedi, dkk., 2018).

Selain sinematografi, Youtuber juga memperhatikan penggunaan tuturan agar intonasi dari narasi-narasi yang mereka utarakan dapat dinikmati oleh pendengar (Elismawati, 2020; Sukmono, 2020). Dengan tuturan yang tidak membosankan dan dapat menarik perhatian, penonton di Youtube tentu akan merasakan kenyamanan dalam 
menyerap informasi yang disampaikan oleh pembuat konten sehingga terus setia pada saluran pilihan mereka.

Secara tidak sadar, Youtuber telah menggunakan strategi bertutur untuk membuat para pengikut mereka tetap menonton konten yang mereka buat, dan bagi penonton yang belum menjadi pelanggan akan menekan tombol subscribe sebagai tanda persetujuan menjadi pelanggan (Ibrahim dan Qura, 2021). Oleh karena itu, penelitian ini membahas tentang strategi bertutur Youtuber profesional dalam menarik minat masyarakat

Menjadi Youtuber dengan pengikut jutaan tidaklah mudah (Ahadyah, 2021; Trisna dan Zulkifli, 2021). Seorang konten kreator Youtube haruslah memiliki kemampuan sinematografi yang baik dan memiliki kemampuan bertutur yang baik agar segala macam informasi yang disampaikan olehnya dapat diterima oleh masyarakat (Aini, dkk., 2021; Evi dan Kafrawi, 2021). Strategi bertutur inilah yang perlu dikaji sebagai bahan pertimbangan dan pembelajaran bagi masyarakat yang ingin masuk ke dunia Youtube, maupun masyarakat yang ingin belajar lebih lanjut tentang berbicara di depan publik (public speaking).

\section{METODE PENELITIAN}

Metode pada penelitian ini yaitu metode kualitatif yang menghasilkan data-data deskripsi berupa kata-kata, kalimat-kalimat, dan gagasan-gagasan tentang sifat, keadaan, gejala, dan motivasi yang muncul dari objek tertentu. Sebagaimana pendapat Moleong (2013:6) menyatakan penelitian kualitatif merupakan suatu sistem kerja penelitian yang menciptakan data-data deskriptif berupa teks-teks tertulis tentang sifat individu, keadaan, gejala dari kelompok tertentu yang dapat diamati.

Teknik pengumpulan data pada penelitian ini menggunakan teknik observasi. Observasi adalah mengumpulkan data atau keterangan yang harus dijalankan dengan melakukan usaha-usaha pengamatan secara langsung ke tempat yang akan diselidiki (Arikunto, 2006: 124). Adapun objek yang menjadi bahan observasi adalah saluransaluran Youtube yang dikelola oleh para Youtuber (nonselebritis) yang telah memiliki pengikut (subscriber) lebih dari satu juta pengikut.

Tabel 1 Daftar Youtuber Indonesia (Objek Penelitian)



Video yang menjadi objek penelitian di atas selanjutnya dibuat transkripsi berdasarkan ucapan pada konten kreator video. Hasil transkripsi tersebut selanjutnya dianalisis menggunakan teori Strategi Bertutur Brown dan Levinson (1987) yang terdiri atas lima unsur antara lain strategi bertutur: 1) berterus terang tanpa basa-basi; 2) dengan basa-basi kesantunan positif; 3) dengan basa-basi kesantunan negatif; 4) samar-samar; dan 5) diam atau dalam hati (Zuve, 2020; Norman, 2021; Husna dan Arief, 2020).. 


\section{HASIL DAN PEMBAHASAN}

\section{Hasil}

Youtuber Jess No Limit, sebagai salah satu Youtuber dengan pengikut paling banyak di Indonesia lebih sering menggunakan strategi bertutur dengan basa-basi positif, sebanyak $40 \%$. Selain itu, Jess No Limit juga terkadang mengeluarkan tuturan yang samar-samar dengan total tuturan sebanyak 20\%, sama dengan jumlah tuturan pada terus terang tanpa basa-basi. Pada Youtuber Jess No Limit, terdapat 15\% strategi dengan basabasi menggunakan pilihan-pilihan kata yang negatif. Terakhir, hanya 5\% strategi bertutur diam/dalam hati.

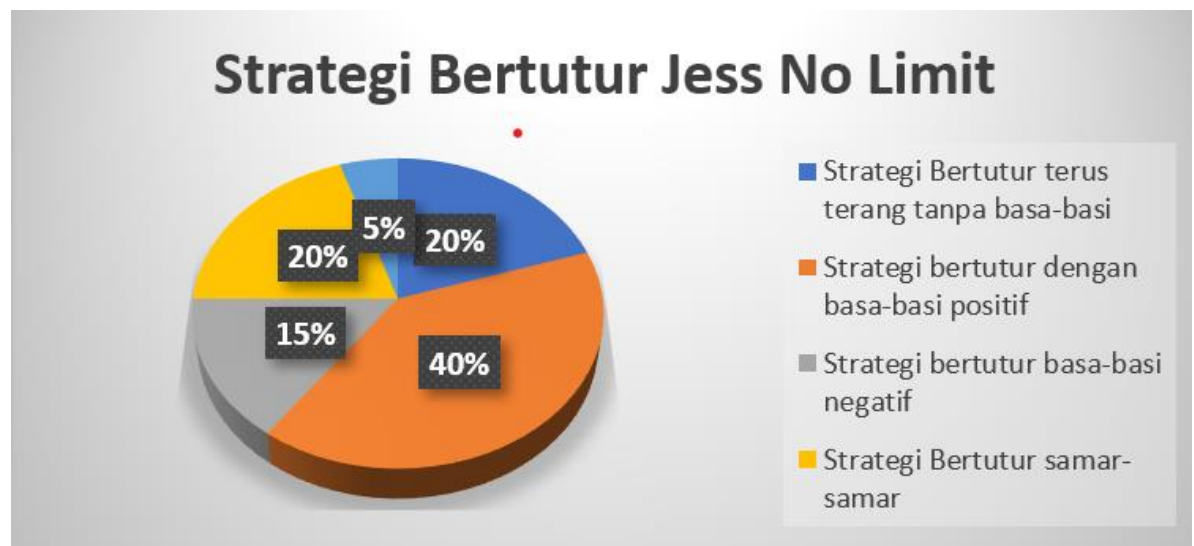

Gambar 1 Strategi Bertutur Jess No Limit

Sumber: Dokumen pribadi, 2020

Sama seperti Jess No Limit, Youtuber MiaAug paling sering menggunakan strategi berbasa-basi positif, sebanyak 40\%. Selain itu, MiaAug juga terkadang mengeluarkan tuturan yang samar-samar dengan total tuturan sebanyak $26 \%$. Pada Youtuber ini, terdapat $22 \%$ strategi bertutur dengan basa-basi menggunakan pilihanpilihan kata yang negatif. Strategi berterus terang tanpa basa-basi terdapat sebanyak $19 \%$. Pada Youtuber MiaAug, tidak ditemukan strategi bertutur diam/dalam hati.



Gambar 2 Strategi Bertutur MiaAug

Sumber: Dokumen pribadi, 2020

Selain Youtuber Gaming, Yudhist Ardana, sebagai Youtuber hiburan lebih sering menggunakan strategi bertutur terus terang tanpa basa-basi. Artinya, Yudhist Ardana lebih mengajak para penontonnya berinteraksi secara langsung pada inti konten yang 
sedang dibawakan. Pada Strategi berutur tanpa basa-basi mencapai persentase $35 \%$. Selain itu, Yudhist Ardana juga lumayan sering menggunakan strategi bertutur samarsamar yaitu sebanyak 30\%. Hanya 20\% strategi dengan basa-basi menggunakan tuturan positif dari Yudhist Ardana, dan 10\% lainnya menggunakan basa-basi negatif. Terakhir, hanya terdapat 5\% strategi bertutur diam/dalam hati dari Yudhist Ardana.

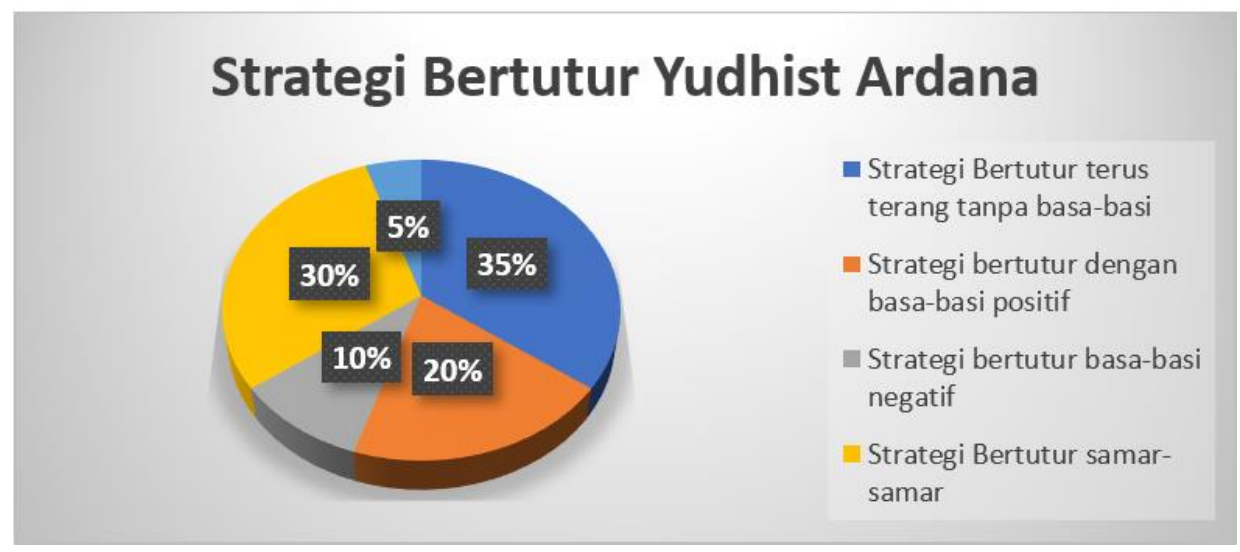

Gambar 3 Strategi Bertutur Yudhist Ardana

Sumber: Dokumen pribadi, 2020

Terakhir, Youtuber Ani Nurhayani yang juga seorang konten kreator video hiburan, paling sering menggunakan strategi bertutur basa-basi dengan diksi-diksi yang lebih positif, sebanyak 38\%. Selain itu, strategi bertutur tanpa basa-basi juga cukup dominan pada Youtuber ini dengan persentase sebanyak 29\%. Untuk strategi samarsamar masih muncul sebanyak $19 \%$ dan basa-basi negatif juga muncul dengan presentase 14\%. Pada Youtuber ini, tidak terdapat strategi bertutur diam/dalam hati karena dalam tiap videonya, Youtuber Ani Nurhayani begitu atraktif dalam berbicara.

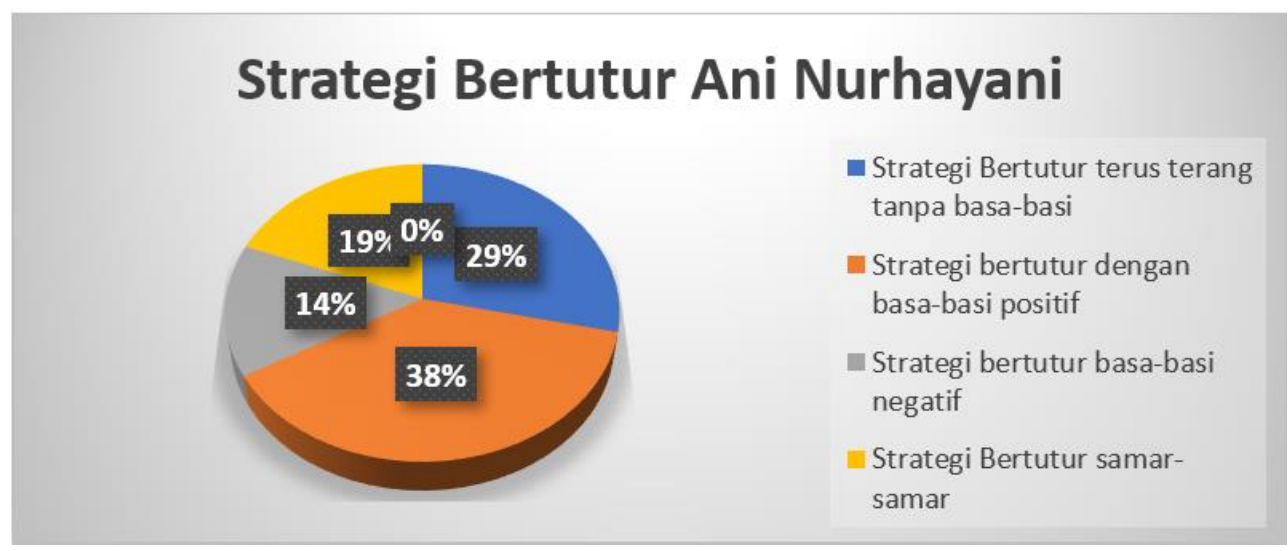

Gambar 4 Strategi Bertutur Ani Nurhayani

Sumber: Dokumen pribadi, 2020

\section{Pembahasan}

Hasil analisis menunjukkan bahwa para konten kreator Youtube (Youtuber) sebagian besar memanfaatkan strategi bertutur dengan basa-basi menggunakan kesantunan yang positif. Hal tersebut dapat terlihat dari persentase yang menunjukkan sebanyak 33\% Youtuber menggunakan strategi tersebut. Selain itu, strategi selanjutnya yang juga dominan muncul adalah strategi berterus-terang tanpa basa-basi dengan 
persentase sebanyak $25 \%$ penggunaan, dan $24 \%$ strategi samar-samar. Strategi bertutur yang jarang muncul adalah strategi bertutur dengan basa-basi menggunakan kesantunan yang negatif sebanyak $16 \%$, dan yang paling sedikit muncul adalah strategi diam atau bertutur dalam hati sebanyak $2 \%$. Secara jelas dapat dilihat pada grafik berikut.



Gambar 5 Strategi Bertutur Youtuber Indonesia

Sumber: Dokumen pribadi, 2020

Sejauh pengamatan peneliti, belum ada penelitian yang secara komprehensif membahas strategi bertutur dengan teori Brown dan Levinson pada beberapa Youtuber secara sekaligus. Adapun penelitian-penelitian relevan yang sejenis masih membahas satu Youtuber sebagai objek kajiannya. Seperti misalnya pada penelitian milik Wulandari dan Utomo (2021) tentang Strategi Bertutur pada Youtuber Jerome Polin. Hasil penelitian tersebut menunjukkan bahwa Jerome Polin lebih cenderung menggunakan strategi tuturan dengan basa-basi dan tanpa basa-basi. Penelitian lain juga pernah dilakukan oleh Laila (2015) menggunakan pendekatan strategi bertutur Grice (1975) pada moderator acara ILC di TVONE. Hasil penelitian Laila menunjukkan bahwa moderator acara ILC menggunakan strategi bertutur dengan cara mengulang jawaban mitra tutur, bertanya pada mitra tutur, menilai mitra tutur, membalikkan jawaban mitra tutur, hingga memojokkan mitra tutur. Penelitian-penelitian relevan tersebut menunjukkan bahwa penelitian tentang strategi bertutur pada konten kreator Youtube belum banyak digeluti oleh peneliti-peneliti terdahulu. Oleh karena itu, penelitian ini memiliki nilai kebaruan yang cukup mutakhir.

Pada hasil penelitian ini, dominasi strategi bertutur basa-basi baik yang positif maupun negatif menandakan bahwa para konten kreator Youtube berusaha dengan keras berinteraksi kepada para penontonnya guna menarik perhatian dan menyenangi kontenkonten video mereka. Tanpa menyampingkan bertutur secara positif, para konten kreator yang notabene anak-anak muda terus mengungkapkan gagasannya melalui pernyataan lisan yang bahkan menerobos pada aspek-aspek kesantunan yang bernuansa negatif ala anak muda. Meskipun begitu, gaya-gaya tuturan yang dilontarkan oleh para konten kreator tersebut justru satu frekuensi dengan keinginan segmentasi penontonnya yang juga merupakan anak-anak muda. Hal ini disebabkan anak-anak muda lebih menyenangi pengungkapan pernyataan yang lebih sederhana dan mudah dipahami (Swandi, 2017; Azizah, 2019; Suleman dan Islamiyah, 2018). 
Selanjutnya, adapun strategi bertutur terus terang tanpa basa-basi yang juga sering muncul menunjukkan bahwa ada Youtuber yang lebih suka untuk langsung pada inti kontennya agar tidak bertele-tele dan membuat para penontonnya jenuh. Seperti pada konten-konten Yudhist Ardana, strategi yang menonjol pada video-video dalam saluran Youtube Yudhist Ardana lebih dominan menggunakan strategi bertutur tanpa basa-basi. Meskipun begitu, gaya penyampaian Yudhist Ardana yang sederhana menyebabkan konten videonya banyak digemari oleh para pemirsa Youtube.

Bagi pada Youtuber, bertutur dengan samar-samar (tidak jelas) merupakan strategi bertutur yang kurang bagus bagi konten-konten yang mereka buat, sehingga sebisa mungkin dihindari. Akan tetapi, strategi bertutur samar-samar ini tetap muncul dan dapat didengar oleh para penontonnya. Minimnya temuan tentang strategi samar-samar ini tentu berkaitan erat dengan prinsip berbicara yang harus diutarakan secara baik dan lancar, dengan nada, intonasi, dan ekspresi yang baik agar para pemirsanya dapat menikmati tayangan secara maksimal (Utami, 2016; Qoriyanti, 2017; Dadela, dkk., 2021).

Yang paling dihindari oleh para konten kreator Youtube adalah strategi bertutur diam atau bertutur dalam hati. Hal ini tentunya berkaitan dengan interaksi yang harus lancar dan interaktif agar para penonton tidak jenuh. Jika seorang Youtuber menjeda tuturannya terlalu lama saat dalam proses syuting, maka dikhawatirkan membuat mereka tidak mendapatkan pelanggan (subscriber), atau penonton yang sebelumnya telah menjadi subscriber pun lama-kelamaan akan meninggalkan tayangan yang membosankan itu. Hal ini terjadi karena penonton sebagai penerima pesan informasi tidak mendapatkan informasi yang diinginkan dengan baik dari penuturnya (Nurhadi dan Kurniawan, 2018)

Strategi-strategi bertutur yang digunakan oleh para konten kreator Youtube sedikit banyaknya tentu akan memengaruhi jumlah pengikut serta penontonnya. Akan tetapi, setiap penonton suatu konten Youtube tentu akan tergolongkan sendirinya sesuai dengan segmentasi konten yang dituju. Untuk konten seperti Youtube game online, segmentasinya tentu akan menyasar ke anak-anak muda dan remaja-khususnya lakilaki-yang merupakan penggemar video game. Pembawaan konten kreator game online yang lebih banyak menggunakan strategi bertutur dengan basa-basi baik positif maupun negatif lebih mudah diterima oleh segmentasi anak-anak muda yang senang berbasa-basi dan berbicara ke sana-kemari mengiringi konten yang tengah dibawakan.

Di sisi lain, berbeda dengan konten-konten hiburan yang lebih bersifat umum, tentu akan lebih menyasar pada penonton yang lebih luas, tidak hanya dinikmati oleh anak-anak muda, tapi juga dewasa, anak-anak, baik laki-laki maupun perempuan. Seperti pada konten Yudhist Ardhana dan Ani Nurhayani yang penontonnya banyak ditemukan anakanak perempuan serta remaja perempuan. Seperti pada konten Yudhist Ardhana misalnya, pembawaan strategi bertutur yang lebih terarah tanpa terlalu banyak berbasa-basi memiliki segmentasinya sendiri dan tetap mendapatkan penonton yang jumlahnya banyak. Artinya, setiap strategi bertutur yang dominan digunakan oleh para konten kreator Youtube memiliki pangsa pasarnya sendiri-sendiri

\section{SIMPULAN}

Para konten kreator Youtube (Youtuber) sebagian besar memanfaatkan strategi bertutur basa-basi dengan kesantunan positif. Hal tersebut dapat terlihat dari persentase yang menunjukkan sebanyak 33\% Youtuber menggunakan strategi tersebut. Selain itu, strategi selanjutnya yang juga dominan muncul adalah strategi bertutur tanpa basa-basi dengan persentase sebanyak $25 \%$ penggunaan, dan $24 \%$ strategi samar-samar. Strategi 
bertutur yang jarang muncul adalah strategi dengan basa-basi dengan kesantunan yang negatif sebanyak $16 \%$, dan yang paling sedikit muncul adalah strategi diam atau bertutur dalam hati sebanyak $2 \%$.

\section{DAFTAR PUSTAKA}

Ahadyah, F. B. (2021). Fenomena Ketertarikan Remaja terhadap Profesi Menjadi Youtuber. Urban Communication and Development Journal, 1(2).

Aini, S. N., A'yun, B. A. Q., Pradipta, E. D., Akalili, A., \& Kulau, F. (2021). Analisis Retorika Visual Pada Konten Youtube Kanal Skinnyindonesian24 Dengan Judul "Youtube Lebih Dari Tv". SOCIA: Jurnal Ilmu-Ilmu Sosial, 18(1), 30-48.

Arikunto, S. 2006. Metode Penelitian Kualitatif. Jakarta: Bumi Aksara.

Artero, J. P. (2010). Online video business models: YouTube vs. Hulu. Palabra clave, 13(1), 111-123.

Azizah, A. R. A. (2019). Penggunaan Bahasa Indonesia Dan Bahasa Gaul Di Kalangan Remaja. Jurnal Skripta, 5(2).

Brown, P., \& Levinson, S. (1987). Politeness: Some Universal in Language Usage. Cambridge University Press.

Cecariyani, S. A., \& Sukendro, G. G. (2018). Analisis Strategi Kreatif dan Tujuan Konten Youtube (Studi Kasus Konten prank Yudist Ardhana). Prologia, 2(2), 495-502.

Cikita, A., \& Murwonugroho, W. (2018, October). Analisis Kebaruan Komposisi Simetrik Pada Kedinamisan Visual Film "Fantastic Mr. Fox". In Prosiding Seminar Nasional Cendekiawan (pp. 873-878).

Dadela, R., Bulan, D. R., \& Hermawan, D. (2021). Pemanfaatan Youtube Sebagai Bahan Ajar Berbicara Bagi Pembelajar BIPA. Deiksis: Jurnal Pendidikan Bahasa dan Sastra Indonesia, 8(1), 61-76.

Elismawati, R. (2020). Penyimpangan Kesantunan Berbahasa Leech Dalam Vlog (Video Blog) Youtubers Indonesia. Universitas Muhammadiyah Jember.

Evi, E., \& Kafrawi, M. (2021). Sinematografi Pelatihan Pembuatan Film Bersama Teater Matan dan Mahasiswa FIB Unilak. BIDIK: Jurnal Pengabdian kepada Masyarakat, 1(2), 20-24.

Giguere, E. (2005). Make easy money with Google: using the AdSense advertising program. Peachpit Press.

Harahap, S. R. (2019). Teknik Sinematografi Dalam Menggambarkan Pesan Optimisme Melalui Film Tenggelamnya Kapal Van Der Wijck. Pena Cendikia, 1(1)

Husna, L. L., \& Arief, E. (2020). Strategi Kesantunan Bertutur Mahasiswa Kepada Dosen Melalui Komunikasi WhatsApp. Jurnal Pendidikan Bahasa dan Sastra Indonesia, 9(4), 13-22.

Ibrahim, N., \& Qura, U. (2021). Speech Acts Used By A Gaming Youtuber In An Online Game Video. RETORIKA: Jurnal Bahasa, Sastra, dan Pengajarannya, 14(2).

Id.influencer.com (2020). Top 100 Youtubers Terbanyak Disubscribed di Indonesia. Dikutip dari: https://id.noxinfluencer.com/youtube-channel-rank/top-100-id-allyoutuber-sorted-by-subs-weekly pada 25 April 2020.

Junaedi, H., Hariadi, M., \& Purnama, I. K. E. (2018). Penerapan Sinematografi Dalam Penempatan Posisi Kamera Dengan Menggunakan Logika Fuzzy. Khazanah Informatika: Jurnal Ilmu Komputer dan Informatika, 4(2), 55-61.

Laila, M. (2015). Strategi bertutur moderator untuk menggali informasi dalam diskusi Indonesia Lawyers Club. PROSIDING PRASASTI, 382-386. 
Moleong, Lexy J. 2013. Metode Penelitian Kualitatif: Edisi Revisi. Bandung: Remaja Rosdakarya.

Moriansyah, L. (2015). Pemasaran melalui media sosial: antecedents dan consequences social media marketing: antecedents and consequenc-es. Jurnal Penelitian Komunikasi dan Opini Publik, 19(3), 187-196.

Norman, M. N. (2021). Kesantunan Imperatif Dan Strategi Bertutur Guru-Siswa. Sertaimplikasinya Dalam Pembelajaran Bahasa Indonesia. Bahasa Indonesia Prima (BIP), 3(1), 92-100.

Nurhadi, Z. F., \& Kurniawan, A. W. (2018). Kajian Tentang Efektivitas Pesan dalam Komunikasi. Jurnal Komunikasi Universitas Garut: Hasil Pemikiran dan Penelitian, 3(1), 90-95.

Priambada, S. (2015). Manfaat penggunaan media sosial pada usaha kecil menengah (UKM). SESINDO 2015, 2015.

Qoriyanti, M.Y.S. (2017). Keterampilan Berbicara Menjadi Sebuah Profesi. Jurnal Pendidikan Bahasa, 6(1), 1-9.

Rini, E., \& Imran, A. (2017). Pengaruh Terpaan Tayangan Traveling Channel Di Youtube Terhadap Minat Berwisata Subscribers Di Indonesia (studi Pada Subscribers Traveling Channel Youtube Ponti Ramanta). eProceedings of Management, 4(1).

Riyadi, T. (2014). Sinematografi Dengan Kamera Dslr. Humaniora, 5(2), 919-929.

Romdonny, J., \& Rosmadi, M. L. N. (2018). Peran Media Sosial Dalam Mendukung Pemasaran Produk Organisasi Bisnis. Ikra-Ith Ekonomika, 1(2), 25-30.

Sukmono, N. D. (2020). Sarkasme Pada Post-Literasi Dan Pra-Literasi Dalam Media Youtube (Kanal Game Online). Jurnal Pendidikan Modern, 5(3), 102-113.

Suleman, J., \& Islamiyah, E. P. N. (2018, October). Dampak Penggunaan Bahasa Gaul di Kalangan Remaja Terhadap bahasa Indonesia. In Prosiding Seminar Nasional Bahasa dan Sastra Indonesia (SENASBASA) (Vol. 2, No. 2).

Swandy, E. (2017). Bahasa gaul remaja dalam media sosial Facebook. Jurnal Bastra (Bahasa dan Sastra), 1(4).

Trisna, N. M. S. W., \& Zulkifli, F. F. (2021). Bisnis Kreatif Di Era Digital Dengan Mengangkat Kearifan Lokal. Jurnal Da Moda, 2(2), 42-47.

Ulfiana, E. (2018). Wacana Iklan Komersial Busana Wanita dalam Media Sosial Instagram. BUANA GENDER: Jurnal Studi Gender dan Anak, 3(1).

Utami, S. (2016). Pengaruh Kemampuan Berbicara Siswa melalui Pendekatan Komunikatif dengan Metode Simulasi pada Pembelajaran Bahasa Indonesia. Likhitaprajna, 18(2), 58-66.

Werdani, R. E., Kurniawati, N. I., Sukoco, J. B., Windriya, A., \& Iskandar, D. (2020). Pelatihan pemasaran produk homemade melalui sosial media. JPPM (Jurnal Pengabdian dan Pemberdayaan Masyarakat), 4(1), 1-5.

Werdani, R. E., Kurniawati, N. I., Sukoco, J. B., Windriya, A., \& Iskandar, D. (2020). Pelatihan pemasaran produk homemade melalui sosial media. JPPM (Jurnal Pengabdian dan Pemberdayaan Masyarakat), 4(1), 1-5.

Wulandari, E., \& Utomo, A. P. Y. (2021). Analisis Tindak Tutur Representatif Dalam Video “Trik Cepet Jawab Soal Matematika Bahasa Inggris Versi Jerome!” Pada Saluran Youtube Jerome Polin. Jurnal Sastra Indonesia, 10(1), 65-70.

Zuve, F. O. (2020, January). Strategi Bertutur Media Online Indonesia. In Seminar Bahasa dan Sastra Indonesia (Vol. 2, No. 1, pp. 79-83) 